\title{
Diversificação, mercantilização e desempenho da educação superior brasileira
}

\author{
Diversification, commodification and \\ performance of Brazilian higher education
}

\begin{abstract}
Rosangela Fritsch ${ }^{\mathbf{1}}$ - Universidade do Vale do Rio dos Sinos | Programa de Pós-Graduação em Educação | São Leopoldo | RS | Brasil. Contato: rosangelaf@ unisinos.br. ORCID: http://orcid.org/0000-0002-0630-3649
\end{abstract} Artur Eugênio Jacobus ${ }^{2}$ - Universidade do Vale do Rio dos Sinos | Programa de Pós-
Graduação em Gestão Educacional | Porto Alegre | RS | Brasil. Contato: jacobus@ @unisinos.br.
ORCID: http://orcid.org/0000-0001-5471-9676

Ricardo Ferreira Vitelli ${ }^{3}$ - Universidade do Vale do Rio dos Sinos | Programa de PósGraduação em Gestão Educacional | Porto Alegre | RS | Brasil. Contato: vitelli@unisinos.br . ORCID: http://orcid.org/0000-0002-8023-9163

\begin{abstract}
Resumo: O presente artigo tem como objetivo analisar o desempenho da Educação Superior Brasileira considerando as especificidades das diferentes categorias administrativas e os fluxos de estudantes de cursos de graduação em um contexto de expansão, diversificação e mercantilização. Configura-se como pesquisa bibliográfica e estudo descritivo de coorte de ingressantes na educação superior em 2010, com dados produzidos pelo INEP. Os resultados apontam para a fragmentação, flexibilização e heterogeneidade do ensino superior brasileiro, bem como para a expansão das IESs e a ampliação das condições de acesso, porém com desempenho limitado, se considerados os indicadores de trajetória dos ingressantes. O sistema de ensino superior brasileiro está sendo configurado em grande parte como um mercado, cada vez mais em mãos de instituições privadas nacionais e internacionais com fins lucrativos, cujo objetivo, em grande parte, se limita a oferecer serviços educacionais que não necessariamente conduzem à conclusão dos estudos em nível de graduação.
\end{abstract}

Palavras-chave: Educação superior. Graduação. Diversificação. Desempenho.

\begin{abstract}
The present article aims to analyze the performance of Brazilian Higher Education considering the specificities of the different administrative categories and streams of undergraduate students in a context of expansion, diversification and commodification of education. This research consists of a bibliographic research and a descriptive study of a cohort that uses the database of the National Institute of Studies and Research in INEP. The results reveal the fragmentation, flexibilization, heterogeneity of the Brazilian higher education system, as well as the expansion of the HEIs and the access conditions, but with limited performance, considering the graduation rates of the students. The Brazilian higher education system is being shaped largely as a market, and increasingly in the hands of private national and international for-profit institutions, whose purpose tends to be limited to providing educational services that do not necessarily lead to the conclusion of undergraduate studies.
\end{abstract}

Keywords: Higher education. Undergraduate. Diversification. Performance.

- Recebido em: 23 de novembro de 2018 - Aprovado em: 21 de fevereiro de 2020

DOI: http://dx.doi.org/10.1590/S1414-40772020000100006

Este é um artigo publicado em acesso aberto sob uma licença Creative Commons https://creativecommons.org/licenses/by-nc/4.0/ 


\section{Introdução}

Este artigo tem como objetivo analisar o desempenho da Educação Superior Brasileira considerando as especificidades das diferentes categorias administrativas e os fluxos de trajetórias de formação de alunos de cursos de graduação em um contexto marcado pela expansão, diversificação e mercantilização.

Entre 2000 e 2016, ampliou-se significativamente o número de matrículas na educação superior. Soma-se a isso a criação de novos cursos em instituições privadas acrescidos nesse período pelo acesso a vagas por cursos a distância.

\section{Gráfico 1 - Evolução do número de matrículas na Educação Superior brasileira no período 2000-2016}

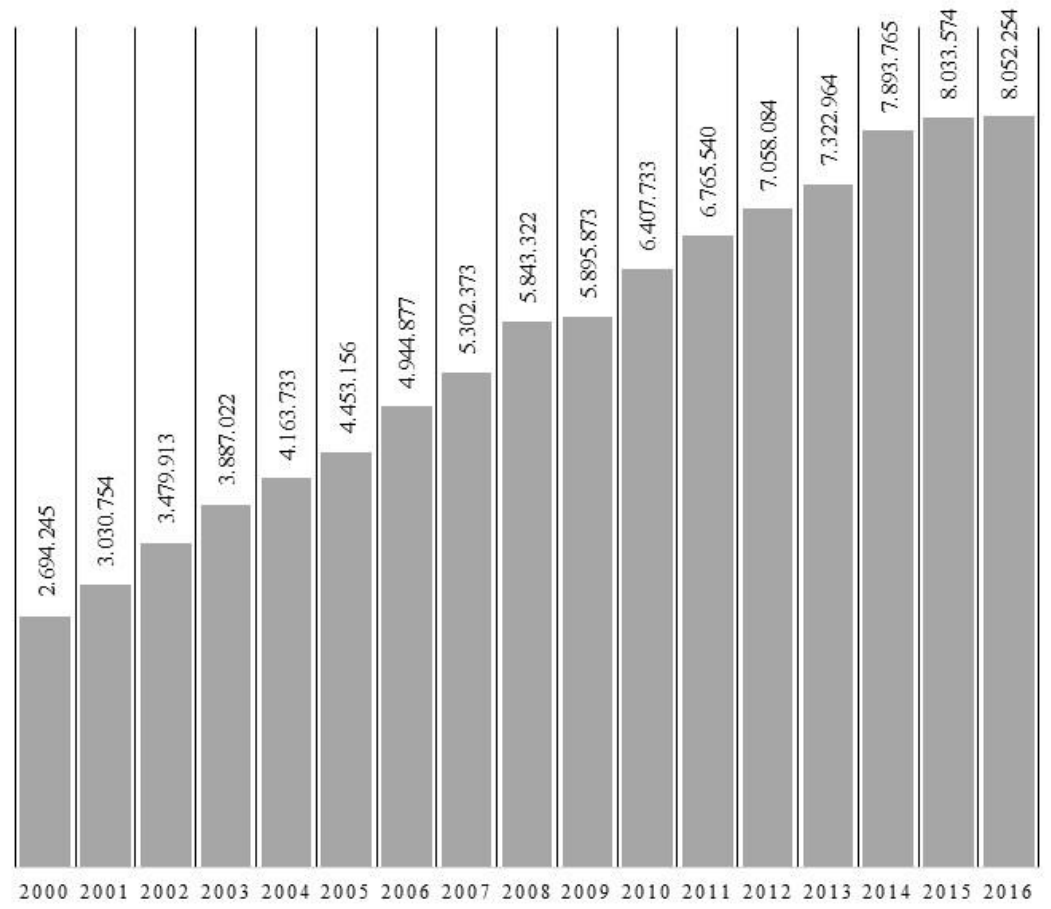

Fonte: INEP (2000-2016).

Entre 2000 e 2016, conforme o gráfico 1, o incremento das matrículas na educação superior brasileira alcançou 198,87\%. Apesar dos programas e políticas públicas de acesso ao Ensino Superior público, grande parte desse acréscimo ocorreu no setor privado. No período, o incremento de matrículas em instituições públicas foi de $124,35 \%$, enquanto nas privadas de 235,25\%. Com isso, aumentou a participação do setor privado na Educação Superior, que, em 2016, respondia por $75,3 \%$ das matrículas, restando $24,7 \%$ ao setor público. A expansão do número de matrículas no ensino superior e o rápido crescimento da participação de instituições privadas estão alinhados com um movimento global que tem privilegiado instituições de 
natureza mercantil e reconfigurado as finalidades e os modelos de universidade (STROMQUIST, 2012; MARTINS, 2008; DIAS SOBRINHO, 2014; SCHWARTZMAN, 2015). Como esse movimento acontece no Brasil de forma acelerada, há necessidade de se acompanhar em que medida as transformações em curso estão sendo eficientes para dar conta da demanda pela educação superior.

A possibilidade de maior acesso não tem sido suficiente para manter os alunos no sistema até a sua diplomação. Altos índices de evasão acabam por desfazer grande parte dos esforços voltados para a inclusão, conforme revelam, ano após ano, os dados estatísticos produzidos pelo INEP (BRASIL, 2017c).

Frente a esse descompasso entre a ampliação do acesso e a evasão de grande parcela dos estudantes, torna-se importante compreender sistemicamente a dinâmica do fluxo escolar dos alunos dos cursos de graduação. Em um cenário em que tantos alunos estudam em cursos de Instituições de Ensino Superior (IESs) privadas, é importante que a análise dos indicadores de percurso dos estudantes considere a natureza pública ou privada das organizações (RISTOFF, 2013; DIAS SOBRINHO, 2013, 2015). É relevante que se distingam instituições privadas, que têm fins lucrativos, das sem fins lucrativos, que podem ser comunitárias, confessionais ou filantrópicas. Esse refinamento analítico se justifica pela crescente participação das instituições com fins lucrativos no segmento do ensino superior brasileiro: essas organizações, que detinham $18,5 \%$ das matrículas do ensino superior privado em 2000, passaram a responder por 49,6\% desse segmento em 2012 (BRASIL, 2016).

Em nível mundial, há um crescimento da participação das organizações com fins lucrativos no ensino superior (ALTBACH; KNIGHT, 2007; MARGINSON; WENDE, 2007; KINSER, 2010; SCHWARTZMAN; PILLAY; PINHEIRO, 2015). Porém, poucos países têm uma presença tão significativa de instituições com fins lucrativos no ensino superior como o Brasil. Países como Chile, África do Sul e Filipinas têm sido citados como alguns dos que possuem um cenário próximo do brasileiro. Em países desenvolvidos, há amplo predomínio de instituições públicas no ensino superior, com espaço limitado para empresas que visam lucro (KINSER, 2010). Mesmo nos Estados Unidos, em que organizações com fins lucrativos alcançaram grande crescimento no começo deste século, chegando a 9,5\% das matrículas na educação pós-secundária em 2010, o setor vem recentemente perdendo espaço, tendo sua participação sido reduzida para apenas 6,2\% em 2015, enquanto, no mesmo ano, as instituições privadas sem fim lucrativo respondiam por $16,5 \%$ do total de matrículas e as públicas por 77,2\% (USA, 2017). 
Estudos sobre as IESs com fins lucrativos têm apontado essas organizações como capazes de atender a um crescimento de demanda que as instituições tradicionais (públicas e privadas sem fins lucrativos) não têm conseguido atender (LECHUGA, 2009; DOUGLASS, 2012). Nos Estados Unidos, as universidades e colleges com fins lucrativos têm focado sua captação no público que costuma ser excluído das instituições tradicionais: empregados em tempo integral, adultos com famílias, estudantes de minorias étnicas etc. A presença desse tipo de aluno nas instituições com fins lucrativos é percentualmente superior à registrada em universidades e colleges públicos ou sem fins lucrativos (LECHUGA, 2009). Sendo assim, os defensores da presença das instituições com fins lucrativos no ensino superior apresentam-nas como organizações capazes de cumprir uma função social que instituições públicas, comunitárias, confessionais e filantrópicas têm tido dificuldade de realizar (DOUGLASS, 2012). Porém, no caso dos Estados Unidos, há indicações de que os alunos de instituições com fins lucrativos têm menor taxa de conclusão da graduação: dados de 2008 indicavam que apenas $22 \%$ concluíam seus estudos em quatro anos, contra $65 \%$ nas instituições privadas sem fins lucrativos e 59\% nas instituições públicas (DOUGLASS, 2012). Essa expressiva retenção de fluxo nas instituições privadas coloca em xeque a eficiência desse segmento naquele país e pode explicar em parte por que sua participação no mercado do ensino superior dos Estados Unidos vem diminuindo nos últimos anos.

Considerando que, no Brasil, as IESs privadas com fins lucrativos respondem por parcela expressiva das matrículas (36,2\% do total em 2012) (CORRÊA, 2015), torna-se importante verificar se a dinâmica do fluxo escolar dos alunos dos cursos de graduação dessas instituições se assemelha ou se diferencia das instituições privadas sem fins lucrativos e das públicas.

Este artigo analisa a distribuição de matrículas por categorias administrativas, tipos de organizações acadêmicas, grau acadêmico, modalidade de ensino e confere especial atenção aos fluxos de formação dos alunos que ingressaram na graduação no ano de 2010, acompanhando-os até 2015. Neste trabalho, o desempenho da graduação no sistema de ensino superior é avaliado tendo como referência as taxas de conclusão, permanência e desistência.

Metodologicamente, este estudo tem como base dados produzidos pelo Instituto Nacional de Estudos e Pesquisas em Educação Anísio Teixeira (INEP), que considerou o ingresso da educação superior em 2010, se configurando então como um estudo descritivo de coorte pois avalia o mesmo grupo de ingressantes até o período de 2015. Busca lançar luz sobre o grau de eficiência que as diferentes formas de oferta de ensino superior têm alcançado no Brasil, seja quanto à duração dos cursos por seus estudantes, seja pelo índice de alunos que 
conseguem concluir seus estudos de graduação, em suas diferentes modalidades. Os resultados são apresentados em gráficos e tabelas a partir dos dados do portal do INEP (planilha Excel e sinopses estatísticas). Nesse arquivo em planilha, são disponibilizados dados censitários de todos os cursos de graduação do Brasil com relação à trajetória dos alunos ingressantes em 2010 até 2015.

As análises se apoiam em pesquisa bibliográfica do tipo revisão de literatura (PIZZANI; SILVA; BELLO; HAYASHI, 2012). Foram analisados artigos sobre Educação Superior no Brasil que abordaram o perfil das IESs, cenário atual e tendências, políticas, modelos e configurações, descartando-se estudos de casos. Foram mapeados documentos no portal do Scientific Eletronic Library Online (Scielo) e no site da Avaliação: Revista Avaliação da Educação Superior ${ }^{1}$, tendo como filtros o recorte temporal de 2008 a 2018 e os descritores "Ensino Superior" e "Educação Superior". A seleção de 44 artigos teve como procedimento a leitura dos títulos e dos resumos.

O texto está estruturado em quatro seções: introdução, revisão bibliográfica, discussão dos resultados e conclusões.

\section{Revisão bibliográfica}

O debate acadêmico sobre o cenário atual da Educação Superior no Brasil pode ser expresso pelas metamorfoses e processos de mercantilização da Educação Superior no mundo e no Brasil como consequências e reflexos do capitalismo global, do projeto neoliberal e do protagonismo do Estado; pelas influências das políticas educacionais mundiais protagonizadas por organismos internacionais e multilaterais e pelo panorama da expansão e das tendências da Educação Superior Brasileira marcado pela fragmentação, flexibilização, heterogeneidade e diversificação de conceitos, configurações e modelos institucionais no âmbito do projeto societário capitalista neoliberal global.

As metamorfoses e os processos de mercantilização da Educação Superior no mundo e no Brasil são reflexo do capitalismo globalizado, do projeto neoliberal e de um Estado a serviço desses interesses (GROPPO, 2011; SERAFIM, 2011; MORGADO, 2009; ROBERTSON, 2009). A emergência de competição de mercado como elemento de regulação por meio de forte

$1 \mathrm{Na}$ área da Educação, na Plataforma Sucupira, Qualis Periódicos, classificação Quadriênio 2013/2016 nas classificações A1 e A2 com o título e foco/escopo na Educação Superior são identificados dois periódicos: Avaliação: revista da avaliação da educação superior, classificação A1, e Ensino Superior Unicamp, classificação A2 que teve encerramento das publicações em agosto de 2017. 
apoio de políticas governamentais configura-se como um fenômeno recente melhor classificado como quase-mercado do que como mercado, visto que combina regulações de Estado com a inserção de alguns mecanismos de mercado (BERTOLIN, 2011).

Stromquist (2012), Martins (2008), Dias Sobrinho (2014) e Schwartzman (2015) exploram, a partir da lógica da sociedade da informação e do conhecimento, a expansão das IESs de natureza mercantil e as reconfigurações das finalidades e modelos da Universidade no sociedade contemporânea: fábrica de conhecimentos e de capitalismo universitário, capitalismo acadêmico. Pereira et al. (2009) entende que a situação atual da vinculação do saber com a sociedade instaura uma nova relação - a do saber-provedor com o usuário-consumidor. "É um saber produto, uma mercadoria, um investimento, um processo de disputa e valor comercial da informação, ciência e tecnologia, que gera a perda do valor do saber como formador do caráter, da moral, da ética, do espírito reflexivo, do cidadão e da construção da nação." (PEREIRA et al., 2009, p. 50).

$\mathrm{Na}$ esteira desse contexto se produz a internacionalização da educação. Lima e Maranhão (2009) definem que a internacionalização ativa é limitada a poucos países, em detrimento da passiva. As influências das políticas educacionais mundiais protagonizadas por organismos internacionais e multilaterais, em relevo o Banco Mundial (BM), determinando reformas na Educação Superior no mundo e no Brasil, são destacadas em várias pesquisas (LIMA; AZEVEDO; CATANI, 2008; LIMA, 2011; BERTOLIN, 2011; DIAS SOBRINHO, 2015).

Algumas pesquisas apontam o processo de Bolonha como uma política educacional supranacional com impactos no sistema universitário no mundo e no Brasil (LIMA; AZEVEDO; CATANI, 2008; SEVERINO， 2009; WIELEWICKI; OLIVEIRA 2010; BERTOLIN, 2011; BIANCHETTI; MAGALHÃES, 2015). Em termos de impactos no Brasil, evidenciam a diversificação das IESs e dos cursos e das fontes de financiamento; o empresariamento da educação superior; a ampliação das parcerias público-privadas e dos contratos de gestão (LIMA; MARANHÃO, 2009; LIMA, 2011; SEGRERA, 2008, 2016).

Nesse sentido, dilui-se o conceito da Educação como bem público em detrimento ao de mercadoria (RISTOFF, 2013). Para Amaral (2016), só será possível atingir os parâmetros da OCDE quando ocorrerem, simultaneamente, três efeitos: estabilidade da população com a diminuição de crianças e jovens em idade educacional; crescimento do país e de seu Produto Interno Bruto (PIB) no contexto do capitalismo mundial; e diminuição das desigualdades sociais existentes. Dias Sobrinho (2015), por sua vez, em relação às Universidades, expõe e 
defende os princípios fundadores e orientadores da universidade pública como instituição central nos processos de construção da existência individual e social.

Adentrando no panorama da expansão e as tendências da Educação Superior Brasileira, as pesquisas apontam para a fragmentação, flexibilização, heterogeneidade e diversificação de conceitos, configurações e modelos institucionais no âmbito do projeto societário capitalista neoliberal global. O problema central é que essa realidade se alicerça no atendimento a demandas do mercado de trabalho, afastando-se da produção, sistematização e disseminação do conhecimento e de valores sociais como a cidadania e a democracia.

Martins (2009) elucida que a implantação da Reforma Universitária de 1968 produziu consequências em termos de inovação ao mesmo tempo que permitiu a emergência de um novo padrão de ensino superior privado no Brasil, organizado como empresas educacionais distintas qualitativamente das universidades públicas e privadas confessionais, justificado pelas demandas de acesso "estruturado nos moldes de empresas educacionais voltadas para a obtenção de lucro econômico e para o rápido atendimento de demandas do mercado educacional" (p. 17).

Dias Sobrinho e Brito (2008) evidenciam a expansão do setor privado e a "expansão livre e duvidosa do setor privado para o lucro" (p. 488). Fato que se evidencia também nas pesquisas de Cunha (2017), para quem algumas universidades comunitárias e confessionais se aproximam das universidades públicas em termos de democratização e qualidade, ao passo que outras tantas instituições com fins lucrativos, algumas de capital internacional, se caracterizam como grandes conglomerados de campus, espalhados pelo país, com propostas de formação de baixo custo, nem sempre de qualidade reconhecida, mesmo que não se possam fazer generalizações.

Mancebo, Silva Júnior e Schugurensky (2016) chamam atenção para o fato de que, para as IESs privado-mercantis, os efeitos da crise não são os mesmos pela forte indução do governo com recursos do ProUni e Fies e "[...] essas empresas também introduziram inovações gerenciais (enxugamento de quadros, precarização do trabalho) e têm adotado um ensino de qualidade discutível, inclusive com o uso intensivo da modalidade a distância" (p. 214).

Público e privado, para Minto (2018), não são tomados como esferas autônomas e predeterminadas, mas examinados em virtude dos conflitos sociais, políticos e econômicos que, no âmbito do ensino superior, expressam disputas em torno de interesses de classe e de visões de mundo antagônicas. $\mathrm{O}$ autor aponta que, a despeito das resistências e mobilizações possíveis durante conferências municipais, estaduais e nacional, no conteúdo do novo Plano Nacional de Educação (PNE), prevalecem os interesses privados no ensino superior. 
Para Sguissardi (2015), no âmbito de uma economia ultraliberal com predominância financeira e de um Estado semiprivado, que lhe é funcional, está sendo anulada a fronteira entre o público e o privado/mercantil, e promovida uma expansão da educação superior que se mantém, de um lado, como de elite e de alta qualificação para poucos, e, de outro, como de massas e de baixa qualificação para muitos, pondo em xeque sua pretendida democratização. A educação superior, no Brasil, vive um intenso processo de transformação: de um direito ou serviço público passando a um serviço comercial ou mercadoria, "isto é, um processo de massificação mercantilizadora que anula as fronteiras entre o público e o privado-mercantil" (p. 869). Marques (2013) considera que, nas décadas de 70 e 80, multiplicaram-se as IES isoladas e, nas décadas seguintes, houve o aumento das instituições particulares e do processo de oligopolização da educação superior (MARQUES, 2013, p. 73).

Para Gomes e Moraes (2012), a transição do sistema de elite (um sistema fechado, meritocrático e altamente seletivo, particularmente destinado a incorporar os membros das classes sociais privilegiadas) para o sistema de educação superior de massa e de baixa qualidade "tem se processado por meio do crescimento do setor privado, que passa a constituir-se como setor hegemônico no tocante ao volume de matrículas" (p. 185).

Severino (2009, p. 258) explicita que a Educação Superior no Brasil é "pressionada de fora pelas injunções de uma dinâmica social escrava do mercado, onde só conta o valor de troca, onde tudo se transforma em mercadoria para um consumo desvairado. Essa dinâmica mercantil induz, por sua vez, uma política atrelada a interesses menores, descompromissados com a construção do bem comum".

Para Dias Sobrinho (2013), não são muito precisos os limites do público e do privado. Lamentavelmente, para muitas instituições privadas (porque nem toda instituição educativa privada é mercantilista e trata o conhecimento como mera mercadoria), sobretudo as mais recentemente criadas, a educação é primordial e quase exclusivamente um empreendimento em função de uma progressiva e ilimitada acumulação de capital econômico. Como tendência geral e ressalvadas poucas e boas exceções, além dos ganhos financeiros de seus proprietários, essas instituições contribuem quase exclusivamente para a intensificação do individualismo possessivo. Nesse caso, a educação é mercadoria, e não patrimônio público (DIAS SOBRINHO, 2013, p. 110-111).

Para Alonso (2010), a lógica de expansão da educação superior incide também sobre a modalidade a distância. Essa forma de oferta, tanto na esfera pública quanta na esfera privada, constitui modelo bastante similar, condicionando a qualidade dos cursos. 
Moraes (2015), tendo como ponto de partida o processo de expansão do ensino superior no século XX, constata que no Brasil o sistema de educação sofre um processo preocupante de americanização, não tão descentralizado e desigualmente financiado como o americano, nem algo tão estruturado, hierarquizado e centralizado quanto o alemão ou o francês.

Sousa (2009) defende a tese de que, no Brasil, historicamente, a política educacional promoveu restrição do público e estímulo à iniciativa privada nesse nível de educação, de forma que "o processo de privatização da educação superior no Brasil e o seu desdobramento na oligopolização recente, mais do que a ausência do Estado, indica, ao contrário da presença deste, que se movimenta no interior de uma cultura política onde os limites entre o público e o privado são obscuros" (p. 81).

Por sua vez, o processo de privatização continua, mas menos acelerado, para Segenreich e Castanheira (2009), pela criação dos Institutos Federais de Educação, Ciência e Tecnologia, pela institucionalização da EaD pela Universidade Aberta do Brasil e sob outras formas, tais como a concessão de bolsas do MEC para o ProUni.

Queiroz et al. (2013) evidenciam que o crescimento das vagas no ensino superior vem apresentando sinais de esgotamento, ocorrendo uma ociosidade no sistema que se manifesta nas vagas não preenchidas nos processos seletivos. As políticas públicas têm um papel fundamental de ajustar a demanda e a oferta, uma vez que há indícios de que a renda é um dos grandes inibidores do preenchimento das vagas e da taxa de sucesso.

O ensino superior público no Brasil no contexto de mercantilização é objeto de análises nas pesquisas de Severino (2008), Lima (2013), Serafim e Dias (2015), Almeida de Carvalho (2015), Spatti, Serafim e Dias (2016).

Severino (2008) mostra o amplo e contínuo processo, conduzido pelo Estado, de reconfiguração organizacional e administrativa e a ambígua política educacional que subjaz a esse processo, adequando o ensino superior nacional às exigências do modelo societário capitalista neoliberal.

Lima (2013) reconhece o mérito do Programa de Apoio a Planos de Reestruturação e Expansão das Universidades Federais, no entanto discute os limites dessas ações na contribuição efetiva para a finalidade a que estavam destinadas, considerando as contradições estruturais do sistema capitalista.

Serafim e Dias (2015) abordam algumas das principais transformações revestidas pela fábula neoliberal, que se naturalizam e são disseminadas sem que sejam devidamente discutidas no ambiente universitário, pelas quais a universidade pública brasileira tem passado ao longo das últimas décadas, mais acentuadamente a partir dos anos 1990: a racionalidade neoliberal, a 
emergência do capitalismo acadêmico, a gênese do inovacionismo e o acirramento do produtivismo na pesquisa.

Na mesma direção, Spatti, Serafim e Dias (2016) desenvolvem a ideia de que as universidades públicas brasileiras vêm passando por transformações significativas ao longo das últimas décadas, deixando de ser um modelo de instituição social e se transformando em uma organização operacional. A expansão das IESs privadas é objeto de estudo nas pesquisas de Martins (2008), Schmidt (2010), Almeida de Carvalho (2013) e Aguiar (2016).

Martins (2008) levanta a preocupação com a qualidade e o crescimento expressivo de empresas com fins lucrativos, em detrimento das comunitárias e ou filantrópicas, identificando um processo de massificação pelo baixo custo em que "se valem de processos seletivos pouco criteriosos no que respeita ao mérito ou bagagem educacional dos 'vestibulandos"” (p. 735).

Schmidt (2010) aponta que a mobilização das instituições comunitárias de educação superior no Brasil em favor de um marco legal próprio reforça o discurso comunitário sob o viés do público não estatal, reunindo essas instituições "condições para proporcionar ao país relevantes contribuições ao compartilhar com o Estado e com as organizações da sociedade civil a tarefa de oferecer serviços públicos de qualidade" (p. 10).

Almeida de Carvalho (2013) mapeia o fenômeno recente de mercantilização da educação superior brasileira, dado pelo crescimento das IES lucrativas e a adoção de diversas estratégias de mercado na direção da financeirização, oligopolização e internacionalização.

Aguiar (2016), analisando as principais políticas para o setor privado de educação superior adotadas pelo governo de Luiz Inácio Lula da Silva (2003/2010), demonstra que, apesar de ter realizado políticas para o setor público bastante distintas das do governo de Fernando Henrique Cardoso, no caso do setor privado, houve um aprofundamento das opções políticas já desenvolvidas durante o governo de Cardoso.

Esse conjunto de estudos sobre o cenário atual da Educação Superior no Brasil confirma que se processa, no País, um acelerado processo de mercantilização da Educação Superior decorrente de um projeto neoliberal em escala global, que considera a educação como mercadoria, e não como bem público. A adoção de políticas educacionais influenciadas por organismos internacionais e multilaterais e a forma como se dá a expansão da Educação Superior Brasileira produzem fragmentação, flexibilização, heterogeneidade e diversificação de conceitos, configurações e modelos institucionais que atendem a um projeto societário capitalista neoliberal global. 


\section{Discussão dos resultados}

Nesta etapa, os dados relativos ao ensino superior brasileiro são apresentados em gráficos e tabelas e discutidos a partir das taxas de fluxo escolar e suas diferenças conforme a segmentação dos dados. Estes dados são oriundos do acompanhamento de fluxo realizado pelo INEP, onde estabelece um período de coorte de 2010 a 2015 (até a finalização do artigo) com ingressantes a parir da criação de novos indicadores de fluxo da Educação Superior. São eles: a taxa de permanência (TAP), a taxa de conclusão acumulada (TCA) e a taxa de desistência acumulada (TDA) que são apresentadas e discutidas no decorrer do artigo (BRASIL, 2017a). O gráfico 2 apresenta a participação das Instituições de Ensino Superior (IESs) por tipo de categoria administrativa na distribuição das matrículas. A maior parcela se encontra no ensino privado, com maior participação de instituições sem fins lucrativos $(42,88 \%)$ seguida das com fins lucrativos $(36,17 \%)$.

\section{Gráfico 2 - Distribuição percentual da quantidade de discentes ingressantes em IES, por tipo de} categoria administrativa, em $2010^{2}$

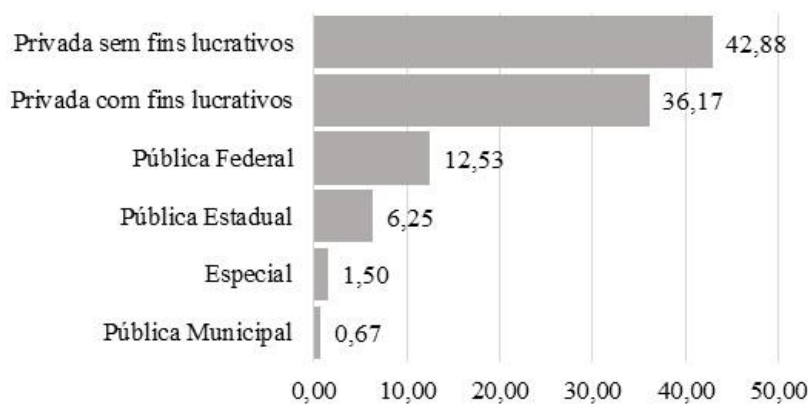

Fonte: BRASIL. Ministério de Educação. Indicadores de fluxo escolar. Brasília, 2017b. Disponível em: http://portal.inep.gov.br/indicadores-educacionais. Acesso em: 24 out. 2017.

O gráfico 2 mostra que as instituições públicas, em 2010, absorveram 19,45\% das matrículas de ingressantes, ao passo que as instituições privadas receberam 79,05\% dos novos alunos em cursos superiores. Essa desequilibrada distribuição das matrículas confirma as análises que apontam o Brasil como um dos países com maior dependência de instituições privadas para a oferta de ensino superior (DOUGLASS, 2012; SCHWARTZMAN; PILLAY; PINHEIRO, 2015). É um cenário muito diferente daquele observado na maioria dos países desenvolvidos, em que o ensino universitário é ofertado majoritariamente por instituições

\footnotetext{
${ }^{2}$ O termo "especial” aparece no documento Brasil (2017b), sem descrição.
} 
públicas, como é o caso, por exemplo, dos Estados Unidos, onde, em 2015, 77,2\% dos estudantes estavam matriculados em universidades e colleges públicos (USA, 2017). De qualquer forma, o caso brasileiro não é isolado, inserindo-se num movimento de mercantilização da educação superior em escala global (GROPPO, 2011; SERAFIM, 2011) e de uma reconfiguração das finalidades e modelos de Universidade, que se movimentam em direção a um modelo denominado por capitalismo universitário (MARTINS, 2008).

Com relação ao tipo de organização acadêmica (gráfico 3), a maior participação é de Universidades $(53,88 \%)$ incluindo públicas e privadas. A comparação dos dados entre os anos de 2010 e 2016 mostra que, com relação à organização acadêmica, as matrículas dos ingressantes não se alteraram, significativamente, em termos de participação percentual sobre o total de ingressantes.

Os Centros Federais de Educação Tecnológica (CFET) que aparecem no gráfico 3 são institutos de ensino brasileiros pertencentes à esfera federal e diretamente ligados ao MEC e com a criação da Rede Federal de Educação Profissional e Tecnológica, muitos desses Centros foram suprimidos e passaram a compor a rede de Institutos Federais de Educação, Ciência e Tecnologia (IFESs).

\section{Gráfico 3 - Distribuição percentual da quantidade de discentes ingressantes em IES, por} organização acadêmica, em 2010 e 2016

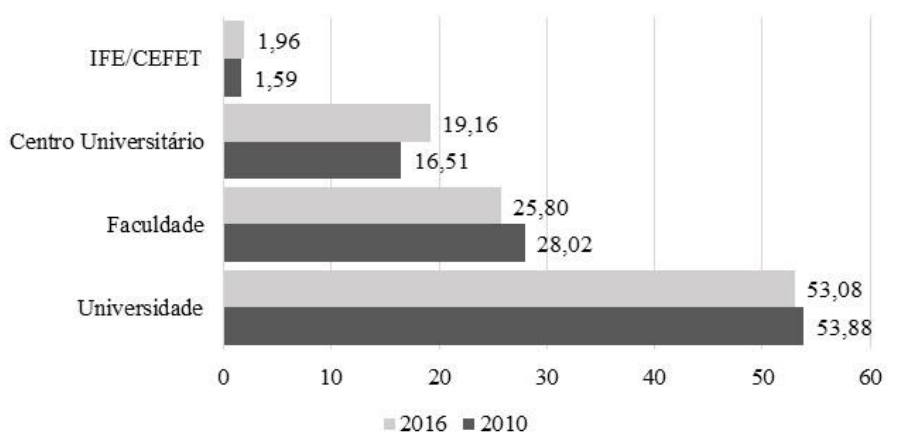

Fontes: BRASIL. Ministério da Educação. Sinopse Estatística da Educação Superior 2010. Brasília, 2011. Disponível em: http://portal.inep.gov.br/web/guest/sinopses-estatisticas-da-educacao-superior. Acesso em: 29 mar. 2018. BRASIL. Ministério de Educação. Indicadores de fluxo escolar. Brasília, $2017 \mathrm{~b}$. Disponível em: http://portal.inep.gov.br/indicadores-educacionais. Acesso em: 24 out. 2017: BRASIL. Instituto Nacional de Estudos e Pesquisas em Educação - Anísio Teixeira. Sinopse Estatística da Educação Superior 2016. Brasília: Inep, 2017c. Disponível em:

http://portal.inep.gov.br/web/guest/sinopses-estatisticas-da-educacao-superior. Acesso em: 10 abr. 2018.

O Gráfico 3 revela uma relativa estabilidade na distribuição das matrículas de ingressantes conforme o tipo de organização acadêmica, apontando para a coexistência, no Brasil, de uma formação em nível superior que acontece tanto em instituições que estão 
comprometidas com o ensino e a pesquisa como em instituições que se dedicam prioritariamente ao ensino. $\mathrm{O}$ fato de que quase metade dos estudantes brasileiros do ensino superior não estuda em universidades é resultado de uma política de diferenciação institucional que tem recebido o estímulo de organismos internacionais, como BIRD e UNESCO (ALMEIDA DE CARVALHO, 2015), que propõem a crescente oferta de formação em nível superior focada na adequação a demandas do mercado de trabalho, conferindo, a grande parte do ensino superior brasileiro, uma função essencialmente profissionalizante.

A participação da quantidade de discentes ingressantes em 2010, por região geográfica brasileira, é representada no gráfico 4. Naturalmente o esperado é que regiões com maior quantidade de população tenham maior quantidade de matrículas. Contudo, associando-se a informação de percentual de ingressantes com o percentual de população na faixa de idade de 15 a 29 anos no ano de 2010, é possível verificar algumas distorções (BRASIL, 2011).

Enquanto na Região Norte a população nessa faixa etária representa 9,16\% do total nacional, apenas 5,35\% do total de matrículas corresponde a estudantes dessa região. Essa situação também se verifica na Região Nordeste, ainda com maior intensidade $(28,74 \%$ da população entre 15 e 29 anos, mas apenas 16,27\% das matrículas). Com isso, se acentuam as desigualdades de acesso ao ensino superior.

Gráfico 4 - Distribuição percentual da quantidade de discentes ingressantes em IES e do percentual da população de 15 a 29 anos, por região geográfica do Brasil, em 2010

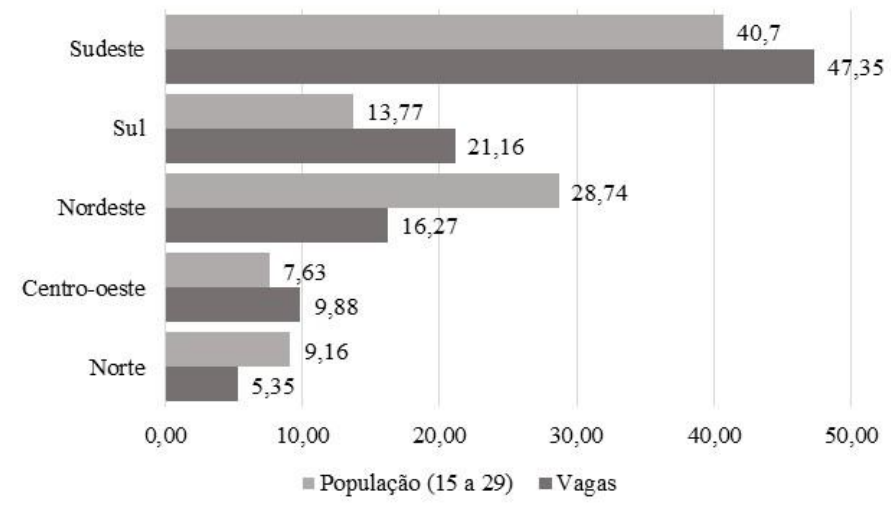

Fonte: BRASIL. Ministério de Educação. Indicadores de fluxo escolar. Brasília, 2017b. Disponível em: http://portal.inep.gov.br/indicadores-educacionais. Acesso em: 24 out. 2017.

Apesar dos discursos e das políticas que têm promovido a diversificação de modelos de ensino superior como forma de democratizar o acesso a esse nível, são ainda percebidas significativas desigualdades regionais. Essas diferenças indicam que, apesar do gradual aumento do percentual de jovens brasileiros que ingressam em cursos de graduação, a 
universalização do acesso à educação superior continua sendo uma intenção que enfrenta grandes dificuldades para se efetivar.

Quando o critério de análise é a modalidade de ensino ofertada, percebe-se uma acelerada mudança de cenário num espaço de apenas seis anos. Os dados do gráfico 5 indicam uma parcela maior de cursos presenciais $(83,11 \%)$ sobre a modalidade EaD $(16,89 \%)$ em 2010. Porém, a participação da educação a distância tem aumentado rapidamente. Em 2016, já atingia a marca de 28,24\% do total dos ingressantes na Educação Superior.

\section{Gráfico 5 - Distribuição percentual da quantidade de discentes ingressantes em IES, por modalidade de ensino, em 2010 e 2016}

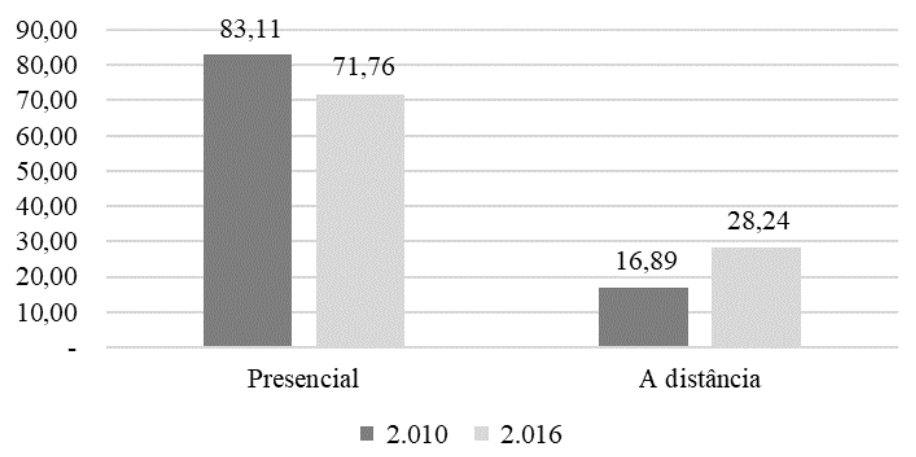

Fonte: BRASIL. Ministério de Educação. Indicadores de fluxo escolar. Brasília, 2017b. Disponível em: http://portal.inep.gov.br/indicadores-educacionais. Acesso em: 24 out. 2017.

O rápido crescimento da educação a distância na educação superior brasileira revela que a flexibilização e diversificação de modelos de formação em nível superior está acontecendo em grande parte por meio da modalidade de ensino. Também essa tem sido a justificativa visando à democratização do acesso, tanto por parte de instituições públicas como privadas (ALONSO, 2010). O percentual de alunos matriculados em cursos totalmente a distância revela, mais uma vez, que o Brasil adota, em suas políticas para o ensino superior, o receituário dos organismos internacionais de forma mais intensa do que a maioria dos países desenvolvidos, que contam com menor percentual de universitários em cursos a distância - nos EUA, em 2015, esse percentual era de 15,4\% (EUA, 2017).

Nas tabelas seguintes foram sumarizados os dados de matrículas de ingressantes em cursos de graduação, levando em consideração as informações disponibilizadas pelo MEC. Assim, a totalização dos dados é feita pela soma dos dados dos cursos por tipo de segmentação (instituições públicas e privadas com e sem fins lucrativos). 
A tabela 1 mostra as trajetórias dos ingressantes em $\mathrm{IES}^{3}$ em 2010 até o ano de $2015^{4}$. Com o ingresso em 2010, é possível, por um estudo de coorte, investigar a trajetória desses estudantes ao longo do tempo. Ao final de um período de seis anos, dos ingressantes em 2010, 10,26\% ainda permaneciam nos cursos (taxa de permanência - TAP), 37,10\% conseguiram concluir o seu curso (taxa de conclusão acumulada - TCA) e 50,83\% abandonaram os cursos (taxa de desistência acumulada - TDA). Esses dados mostram que, a cada 100 ingressantes em 2010, aproximadamente 37 conseguiram concluir seus cursos em seis anos e em torno de 50 deles abandonaram o ensino superior no mesmo período. Com ingresso em 2010, ao final daquele mesmo ano, aparecem 28.973 formados, fato que está relacionado ao ingresso de alunos por transferência ou reingresso de diplomado, que conseguem se diplomar no mesmo ano do ingresso.

Tabela 1 - Representação da trajetória dos discentes ingressantes em 2010 até 2015

\begin{tabular}{c|r|r|r|r|r|r}
\hline Ano & $\begin{array}{c}\text { Permanecem } \\
\text { no curso }\end{array}$ & $\begin{array}{c}\text { Percentual } \\
\text { do ano }\end{array}$ & $\begin{array}{c}\text { Concluíram } \\
\text { o curso }\end{array}$ & $\begin{array}{c}\text { Percentual } \\
\text { acumulado }\end{array}$ & $\begin{array}{c}\text { Desistiram } \\
\text { do curso }\end{array}$ & $\begin{array}{c}\text { Percentual } \\
\text { acumulado }\end{array}$ \\
\hline 2010 & 2.201 .772 & $97,45 \%$ & 28.973 & $1,32 \%$ & 27.015 & $1,23 \%$ \\
2011 & 1.702 .383 & $77,32 \%$ & 80.406 & $4,97 \%$ & 418.694 & $20,24 \%$ \\
2012 & 1.292 .999 & $58,73 \%$ & 141.818 & $11,40 \%$ & 267.349 & $32,39 \%$ \\
2013 & 896.150 & $40,70 \%$ & 216.369 & $21,24 \%$ & 180.282 & $38,06 \%$ \\
2014 & 484.175 & $21,99 \%$ & 246.370 & $32,43 \%$ & 165.482 & $45,58 \%$ \\
2015 & 231.625 & $10,26 \%$ & 163.705 & $37,10 \%$ & 88.764 & $50,83 \%$ \\
Total & 231.625 & $10,26 \%$ & 837.641 & $37,10 \%$ & 1.147 .586 & $50,83 \%$ \\
\hline
\end{tabular}

Fonte: BRASIL. Ministério de Educação. Indicadores de fluxo escolar. Brasília, 2017b. Disponível em: http://portal.inep.gov.br/indicadores-educacionais. Acesso em: 24 out. 2017.

A tabela 1 revela a trajetória dos ingressantes de 2010 em cursos de graduação. Portanto, os dados mostram a progressão desses alunos no curso em que ingressaram naquele ano, o que não necessariamente corresponde à trajetória deles na instituição ou no sistema de ensino superior, pois uma parte dos alunos que desistiram do curso podem ter ingressado em outro ou migrado para outra instituição de ensino. Percebe-se que as taxas de conclusão de curso acontecem com maior intensidade entre o $4^{\circ}$ e o $5^{\circ}$ ano de formação, ao passo que o percentual

\footnotetext{
${ }^{3}$ Nesse número, são consideradas todas as formas de ingresso, incluindo o ingresso por transferência. Por esse motivo, os dados não são iguais a outros estudos que tratam do ingresso apenas por vestibular, em função das vagas nas IES.

${ }^{4}$ O INEP, em 2017, divulgou uma nova metodologia de avaliação de indicadores de percurso dos estudantes, classificando-os em: taxa de permanência (TAP), taxa de conclusão acumulada (TCA) e taxa de desistência acumulada (TDA). As trajetórias dos alunos nos percursos educacionais formais, conforme o INEP, são estruturadas a partir dos currículos dos seus cursos. Dessa forma, pode-se acompanhar cronologicamente a trajetória dos alunos a partir de seu ingresso em um itinerário formativo.
} 
de desistência mais expressivo acontece no $2^{\circ}$ ano de curso. Depois, embora continue crescendo cumulativamente, a evasão diminui de ritmo. A maior probabilidade de evasão nos primeiros semestres de curso tem sido apontada nos estudos sobre evasão, tanto no Brasil (FRITSCH; ROCHA; VITELLI, 2015; SANTOS JÚNIOR; REAL, 2017) como no exterior (TINTO, 1993).

Conforme os dados, ao final de seis anos, cerca de $50 \%$ dos ingressantes em cursos de graduação haviam desistido de seus cursos, e apenas 37,10\% haviam se diplomado. Esses números indicam que, apesar do expressivo crescimento do número de matrículas ao longo dos primeiros anos deste século, existe uma significativa distância entre acesso e sucesso no ensino superior: a maioria dos alunos que ingressaram em 2010 não obteve êxito após seis anos de estudos.

Na tabela 2, a trajetória dos estudantes foi mapeada a partir de uma segmentação em relação à categoria administrativa das IESs. Ainda tomando por base os ingressantes em 2010, foram analisadas as taxas segmentadas entre IES públicas e privadas, sendo que as últimas também foram segmentadas entre com e sem fins lucrativos.

Os resultados mostram que as IESs públicas retêm (TAP) mais os alunos do que as privadas, mas têm menor taxa de desistência (TDA). As instituições públicas superam as privadas quanto ao percentual de concluintes (TCA) após seis anos, mas, em todas elas, a taxa de sucesso após seis anos é muito reduzida, variando de 32,84\% nas privadas sem fins lucrativos a 37,61\% nas instituições públicas. A diferença de desempenho é mais pronunciada quando se examina a taxa de desistência acumulada no período entre 2010 e 2015: 44,43\% nas instituições públicas e $58,26 \%$ nas privadas.

Tabela 2 - Representação da trajetória dos discentes ingressantes em 2010 até 2015 por categoria administrativa ${ }^{5}$

\begin{tabular}{|c|c|c|c|c|c|c|}
\hline $\begin{array}{c}\text { Categoria } \\
\text { administrativa }\end{array}$ & $\begin{array}{l}\text { Permanecem } \\
\text { (acumulado) }\end{array}$ & $\begin{array}{l}\text { Concluíram } \\
\text { (acumulado) }\end{array}$ & $\begin{array}{l}\text { Desistiram } \\
\text { (acumulado) }\end{array}$ & TAP & TCA & TDA \\
\hline Total acumulado & 231.625 & 837.641 & 1.147 .586 & $10,26 \%$ & $37,10 \%$ & $50,83 \%$ \\
\hline Públicas & 86.758 & 181.773 & 214.724 & $17,95 \%$ & $37,61 \%$ & $44,43 \%$ \\
\hline Privadas & 143.607 & 688.718 & 1.161 .836 & $7,20 \%$ & $34,54 \%$ & $58,26 \%$ \\
\hline $\mathrm{C} / \mathrm{F}$ & 74.506 & 331.222 & 499.796 & $8,20 \%$ & $36,46 \%$ & $55,01 \%$ \\
\hline $\mathrm{S} / \mathrm{F}$ & 69.101 & 357.496 & 662.040 & $6,35 \%$ & $32,84 \%$ & $60,81 \%$ \\
\hline
\end{tabular}

Observação: C/F indica com fins lucrativos e S/F sem fins lucrativos.

Fonte: BRASIL. Ministério de Educação. Indicadores de fluxo escolar. Brasília, 2017b. Disponível em: http://portal.inep.gov.br/indicadores-educacionais. Acesso em: 24 out. 2017.

\footnotetext{
${ }^{5}$ Não estão incluídas as matrículas da categoria administrativa designada pelo INEP como especial e os dados de taxa de falecimento. Assim, não constam na tabela 2.869 registros na categoria especial, o que impossibilita que alguns totais comparados com o total geral não sejam compatíveis.
} 
Os dados revelam uma convergência quanto ao baixo desempenho de instituições públicas e privadas no percentual de alunos concluintes após seis anos de seu ingresso nos cursos de graduação. Por outro lado, quando o parâmetro de análise é o índice de desistência, percebe-se que o insucesso é bem mais pronunciado nas instituições privadas, especialmente naquelas sem fins lucrativos, em que o índice acumulado de desistência chega a 60,81\% dos ingressantes de 2010. Revela-se, assim, maior eficiência das instituições públicas em relação às privadas quanto ao percentual de alunos que concluem seus estudos de graduação.

\section{Conclusões}

O cenário da Educação Superior brasileira é marcado pela fragmentação, flexibilização, heterogeneidade e diversificação de configurações e modelos institucionais no âmbito do projeto societário capitalista neoliberal global.

Os dados analisados revelam que a expansão das IESs e das condições de acesso não significou melhoria no desempenho, se considerados os indicadores de fluxo. É legítimo que se pergunte o quanto os resultados das taxas de permanência, conclusão e desistência estão próximos ou distantes das metas institucionais referentes ao ensino superior. Porém, um exame do Plano Nacional de Educação em vigor revela que as metas relativas ao ensino superior dizem respeito ao percentual de matrículas, não sinalizando qualquer expectativa quanto ao número de alunos que conseguem concluir seus estudos nesse nível de ensino. Essa omissão do PNE pode ser reveladora de que o sistema de ensino superior brasileiro está sendo configurado como um mercado, cada vez mais em mãos de instituições privadas nacionais e internacionais com fins lucrativos, cujo objetivo, em grande parte, se limita a oferecer serviços educacionais (disciplinas e créditos) a uma crescente parcela de jovens brasileiros menos favorecidos socialmente, porém sem o compromisso de garantir que a "aquisição" desses serviços conduza necessariamente ao principal objetivo que leva ao ingresso em cursos superiores: a diplomação com qualidade social. Os números revelam um mercado em expansão, num processo de massificação do ensino superior que tem a EAD como uma estratégia prioritária, porém sem compromissos nem controle quanto à sua capacidade de gerar os resultados que justificam a própria existência dos cursos superiores.

A expansão da educação superior no Brasil, nas últimas décadas, pautada por um ideário neoliberal combinado com demandas do capitalismo e com uma configuração de Estado Mínimo-Avaliador tem se caracterizado pela mercantilização, privatização, oligopolização, 
massificação e diversificação sem impactos positivos na reversão das desigualdades educacionais e melhoria do desempenho acadêmico dos estudantes.

\section{Referências}

AGUIAR, Vilma. Um balanço das políticas do governo Lula para a educação superior: continuidade e ruptura. Revista de Sociologia e Política, Curitiba, v. 24, n. 57, p. 113-126, mar. 2016. Disponível em: http://www.scielo.br/scielo.php?script=sci_arttext\&pid=S010444782016000100113. Acesso em: 27 mar. 2018.

ALMEIDA DE CARVALHO, Cristina Helena. A mercantilização da educação superior brasileira e as estratégias de mercado das instituições lucrativas. Revista Brasileira de educação, Rio de Janeiro, v. 18, n. 54, p. 761-801, jul./set. 2013. Disponível em: http://www.scielo.br/scielo.php?pid=S141324782013000300013\&script=sci_abstract\&tlng=pt. Acesso em: 27 mar. 2018.

ALMEIDA DE CARVALHO, Cristina Helena. A política pública de expansão para a educação superior entre 1995 e 2010 uma abordagem neoinstitucionalista histórica. Revista Brasileira de Educação, Rio de Janeiro, v. 20, n. 60, p. 51-76, jan./mar. 2015. Disponível em: http://www.scielo.br/pdf/rbedu/v20n60/1413-2478-rbedu-20-60-0051.pdf. Acesso em: Acesso em: 27 mar. 2018.

ALONSO, Kátia Morosov. A expansão do ensino superior no Brasil e a EaD: dinâmicas e lugares. Educação \& Sociedade, Campinas, v. 31, n. 113, p. 1319-1335, out./dez. 2010. Disponível em: http://www.scielo.br/scielo.php?pid=S010173302010000400014\&script=sci_abstract\&tlng=pt. Acesso em: Acesso em: 27 mar. 2018.

ALTBACH, Philip G.; KNIGHT, Jane. The internationalization of higher education: Motivations and realities. Journal of studies in international education, Thousand Oaks, v. 11, n. 3-4, p. 290-305, 2007. Disponível em:

https://journals.sagepub.com/doi/pdf/10.1177/1028315307303542. Acesso em: 27 mar. 2018.

AMARAL, Nelson Cardoso. A educação superior brasileira: dilemas, desafios e comparações com os países da OCDE e do BRICS. Revista Brasileira de Educação, Rio de Janeiro, v. 21, n. 66, p. 717-736, jul./dez. 2016. Disponível em: http://www.scielo.br/scielo.php?pid=S141324782016000300717\&script=sci_abstract\&tlng=es. Acesso em: 27 mar. 2018.

BERTOLIN, Júlio Cesar G. Os quase-mercados na educação superior: dos improváveis mercados perfeitamente competitivos à imprescindível regulação do Estado. Educação e Pesquisa, São Paulo, v. 37, n. 2, p. 237-248, maio/ago. 2011. Disponível em: http://www.scielo.br/scielo.php?pid=S151797022011000200002\&script=sci_arttext\&tlng=pt. Acesso em: 27 mar. 2018.

BIANCHETTI, Lucídio; MAGALHÃES, António. Declaração de Bolonha e internacionalização da educação superior: protagonismo dos reitores e autonomia universitária em questão. Avaliação, Campinas; Sorocaba, v. 20, n. 1, p. 225-249, mar. 2015. Disponível em: https://submission3.scielo.br/index.php/aval/article/view/123336 Acesso em: 27 mar. 2018. 
BRASIL. Ministério da Educação. Instituto Nacional de Estudos e Pesquisas em Educação Anísio Teixeira. Sinopse Estatística da Educação Superior 2010. Brasília, DF. 2011.

Disponível em: http://portal.inep.gov.br/web/guest/sinopses-estatisticas-da-educacao-superior. Acesso em: 29 mar. 2018.

BRASIL. Conselho Administrativo de Defesa Econômica. Atos de Concentração no Mercado de Prestação de Serviços de Ensino Superior. Cadernos do CADE, Brasília, maio 2016. Disponível em: http://www.cade.gov.br/acesso-a-informacao/publicacoes-institucionais/deepublicacoes-anexos/caderno-de-educacao-20-05-2016.pdf. Acesso em: 16 mar. 2018.

BRASIL. Ministério de Educação. Metodologia de cálculo dos indicadores de fluxo da educação superior. Brasília, 2017a. Disponível em:

file:///E:/dados\%20inep/metodologia_indicadores_trajetoria_curso.pdf. Acesso em: 24 out. 2017.

BRASIL. Ministério de Educação. Indicadores de fluxo escolar. Brasília, 2017b. Disponível em: http://portal.inep.gov.br/indicadores-educacionais. Acesso em: 24 out. 2017.

BRASIL. Instituto Nacional de Estudos e Pesquisas em Educação - Anísio Teixeira. Sinopse Estatística da Educação Superior 2016. Brasília: Inep, 2017c. Disponível em:

http://portal.inep.gov.br/web/guest/sinopses-estatisticas-da-educacao-superior. Acesso em: 10 abr. 2018.

BRASIL. Ministério da Educação. Instituto Nacional de Estudos e Pesquisas em Educação Anísio Teixeira. Censos Escolares da Educação Superior 2000-2016. Brasília: Inep, 2017d. Disponíveis em: http://portal.inep.gov.br/censo-da-educacao-superior. Acesso em: 20 nov. 2017.

CORRÊA, Eneida Corrêa de Britto. Modelo regulatório híbrido da educação superior privada: possibilidades, limites e desafios. 2015. Dissertação (Mestrado) - Escola Brasileira de Administração Pública e de Empresa, Centro de Formação Acadêmica e Pesquisa, Rio de Janeiro, 2015.

CUNHA, Maria Isabel da. Qualidade da educação superior e a tensão entre democratização e internacionalização na universidade brasileira. Avaliação, Campinas; Sorocaba, SP, v. 22, n. 3, p. 817-832, nov. 2017. Disponível em:

http://www.scielo.br/scielo.php?script=sci_abstract\&pid=S1414-

40772017000300817\&lng=en\&nrm=iso\&tlng=pt. Acesso em: 27 mar. 2018.

DIAS SOBRINHO, José. Educação superior: bem público, equidade e democratização.

Avaliação, Campinas; Sorocaba, SP, v. 18, n. 1, p. 107-126, mar. 2013. Disponível em:

http://www.scielo.br/scielo.php?pid=S1414-

40772013000100007\&script=sci_abstract\&tlng=pt. Acesso em: 27 mar. 2018.

DIAS SOBRINHO, José. Universidade e novos modos de produção, circulação e aplicação do conhecimento. Avaliação, Campinas; Sorocaba, v. 19, n. 3, p. 643-662, nov. 2014.

Disponível em: http://www.scielo.br/scielo.php?pid=S1414-

40772014000300007\&script=sci_abstract\&tlng=pt. Acesso em: 27 mar. 2018. 
DIAS SOBRINHO, José. Universidade fraturada: reflexões sobre conhecimento e responsabilidade social. Avaliação, Campinas; Sorocaba, v. 20, n. 3, p. 581-601, nov. 2015. Disponível em: http://www.scielo.br/pdf/aval/v20n3/1414-4077-aval-20-03-00581.pdf.

Acesso em: 27 ma. 2018.

DIAS SOBRINHO, José; BRITO, Márcia Regina F. de. La educación superior en Brasil: principales tendencias y desafíos. Avaliação, Campinas; Sorocaba, v. 13, n. 2, p. 487-507, jul. 2008. Disponível em: http://www.scielo.br/scielo.php?script=sci_arttext\&pid=S141440772008000200011. Acesso em: 27 mar. 2018.

DOUGLASS, John Aubrey. The Rise of the For-Profit Sector in US Higher Education and the Brazilian Effect. European Journal of Education, Hanover, EUA, v. 47, n. 2, p. 242-259, jun. 2012. Disponível em: https://onlinelibrary.wiley.com/doi/abs/10.1111/j.14653435.2012.01521.x. Acesso em: 16 mar. 2018.

FRITSCH, Rosangela; ROCHA, Cleonice Silveira; VITELLI, Ricardo Ferreira. A evasão nos cursos de graduação em uma instituição de ensino superior privada. Revista Educação em Questão, Natal, v. 52, n. 38, p. 81-108, maio/ago. 2015. Disponível em: https://periodicos.ufrn.br/educacaoemquestao/article/view/7963. Acesso em: 27 mar. 2018.

GOMES, Alfredo Macedo; MORAES, Karine Numes de. Educação superior no Brasil contemporâneo: transição para um sistema de massa. Educação \& Sociedade, Campinas, v. 33, n. 118, p. 171-190, jan./mar. 2012. Disponível em:

http://www.scielo.br/pdf/es/v33n118/v33n118a11.pdf. Acesso em: 27 mar. 2018.

GROPPO, Luís Antonio. Da universidade autônoma ao ensino superior operacional: considerações sobre a crise da universidade e a crise do Estado nacional. Avaliação, Campinas; Sorocaba, v. 16, n. 1, p. 37-55, mar. 2011. Disponível em:

http://www.scielo.br/scielo.php?pid=S141440772011000100003\&script=sci_abstract\&tlng=pt. Acesso em: 27 mar. De 2018.

KINSER, Kevin. A Global Perspective on For-Profit Higher Education. In: TIERNEY, William G, LECHUGA, Vicente M.; HENTSCHKE, Guilbert (eds.). Learning for Earning in a Globalized Society: for-profit colleges and universities as schools and businesses. Albany, NY: SUNY Press, 2010. p. 145-170.

LECHUGA, Vicente M. The Paradox of For-Profit Higher Education. In: KNAPP, John C.; SIEGER, D. J. (eds.). The Business of Higher Education: management and fiscal strategies. Santa Barbara: Praeger, p. 205-224, 2009.

LIMA, Kátia Regina de Souza. O Banco Mundial e a educação superior brasileira na primeira década do novo século. Revista Katálysis, Florianópolis, v. 14, n. 1, p. 86-94, jan./jun. 2011. Disponível em: http://www.scielo.br/scielo.php?pid=S141449802011000100010\&script=sci_abstract\&tlng=pt. Acesso em: 27 mar. 2018.

LIMA, Paulo Gomes. Políticas de educação superior no Brasil na primeira década do século XXI: alguns cenários e leituras. Avaliação, Campinas; Sorocaba, v. 18, n. 1, p. 85-105, mar. 2013. Disponível em: http://www.scielo.br/scielo.php?pid=S141440772013000100006\&script=sci_abstract\&tlng=pt. Acesso em: 27 mar. 2018. 
LIMA, Licínio C.; AZEVEDO, Mário Luiz Neves de; CATANI, Afrânio Mendes. O processo de Bolonha, a avaliação da educação superior e algumas considerações sobre a Universidade Nova. Avaliação, Campinas; Sorocaba, v. 13, p. 7-37, mar. 2008. Disponível em: http://www.scielo.br/scielo.php?pid=S141440772008000100002\&script=sci_abstract\&tlng=pt. Acesso em: 27 mar. 2018.

LIMA, Manolita Correia; MARANHÃO, Carolina Saraiva. O sistema de educação superior mundial: entre a internacionalização ativa e passiva. Avaliação, Campinas; Sorocaba, SP, v. 14, n. 3, p. 583-610, nov. 2009. Disponível em: http://www.scielo.br/scielo.php?pid=S1414 40772009000300004\&script=sci_abstract\&tlng=pt. Acesso em: 27 mar. 2018.

MANCEBO, Deise; SILVA JÚNIOR, João dos Reis; SCHUGURENSKY, Daniel. A educação superior no Brasil diante da mundialização do capital. Educação em Revista, Belo Horizonte, v. 32, n. 4, p. 205-225, out./dez. 2016. Disponível em:

http://www.scielo.br/scielo.php?pid=S0102-

46982016000400205\&script=sci_abstract\&tlng=pt. Acesso em: 27 mar. 2018.

MARGINSON, Simon; WENDE, Marijk Van Der. Globalisation and higher education. OECD. Education Working Papers, Paris, n. 8, 2007. Disponível em: https://www.oecdilibrary.org/education/globalisation-and-higher-education_173831738240. Acesso em: 16 mar. 2018.

MARQUES, Waldemar. Expansão e oligopolização da educação superior no Brasil. Avaliação, Campinas; Sorocaba, SP, v. 18, n. 1, p. 69-83, mar. 2013. Disponível em: http://www.scielo.br/scielo.php?script=sci_arttext\&pid=S1414$40772013000100005 \& l a n g=p t$. Acesso em: 27 mar. 2018.

MARTINS, André Luiz de Miranda A marcha do "capitalismo universitário" no Brasil nos anos 1990. Avaliação, Campinas; Sorocaba, v. 13, n. 3, p. 733-743, nov. 2008. Disponível em: http://www.scielo.br/scielo.php?script=sci_arttext\&pid=S141440772008000300006\&lang=pt. Acesso em: 27 mar. 2018.

MARTINS, Carlos Benedito. A reforma universitária de 1968 e a abertura para o ensino superior privado no Brasil. Educação \& sociedade, Campinas, SP, v. 30, n. 106, p. 15-35, jan./abr. 2009. Disponível em:

http://www.scielo.br/scielo.php?script=sci_arttext\&pid=S0101$73302009000100002 \&$ lang=pt. Acesso em: 27 mar. 2018.

MINTO, Lalo Watanabe. Educação superior no PNE (2014-2024): apontamentos sobre as relações público-privadas. Revista Brasileira de Educação, Rio de Janeiro, v. 23, e.230011, p. 1-16, 2018. Disponível em: http://www.scielo.br/scielo.php?script=sci_arttext\&pid=S141324782018000100208\&lang=pt. Acesso em: 16 jul. 2018.

MORAES, Reginaldo C. C. Expansão do ensino superior: o que isso nos ensina sobre o vínculo entre as relações sociais e as políticas de educação. Educação \& Sociedade, Campinas, SP, v. 36, n. 130, p. 197-218, jan./mar. 2015. Disponível em: http://www.scielo.br/scielo.php?script=sci_arttext\&pid=S0101$73302015000100197 \&$ lang=pt. Acesso em: 27 mar. 2018. 
MORGADO, José Carlos. Processo de Bolonha e ensino superior num mundo globalizado. Educação \& Sociedade, Campinas, SP, v. 30, n. 106, p. 37-62, jan./abr. 2009. Disponível em: http://www.scielo.br/scielo.php?script=sci_arttext\&pid=S0101$73302009000100003 \&$ lang=pt. Acesso em: 27 mar. 2018.

PEREIRA, Elisabete M. de Aguiar et al. A universidade da modernidade nos tempos atuais. Avaliação, Campinas; Sorocaba, v. 14, n. 1, p. 29-52, mar. 2009. Disponível em: http://www.scielo.br/scielo.php?script=sci_arttext\&pid=S141440772009000100003\&lang=pt. Acesso em: 27 mar. 2018.

PIZZANI, Luciana; SILVA, Rosemary Cristina da; BELLO, Suzelei Faria.; HAYASHI, Maria Cristina P. I. A arte da pesquisa bibliográfica na busca do conhecimento. RDBCI, Campinas, SP, v. 10, n. 1, p. 53-66, jul./dez. 2012. Disponível em: https://periodicos.sbu.unicamp.br/ojs/index.php/rdbci/article/view/1896. Acesso em: 27 mar. 2018.

QUEIROZ, Fernanda C. B. P. et al. Transformações no ensino superior brasileiro: análise das instituições privadas de ensino superior no compasso com as políticas de estado. Ensaio, Rio de Janeiro, v. 21, n. 79, p. 349-370, abr./jun. 2013. Disponível em: http://www.scielo.br/scielo.php?script=sci_arttext\&pid=S010440362013000200009\&lang=pt. Acesso em: 27 mar. 2018.

RISTOFF, Dilvo. Os desafios da educação superior na Ibero-américa: inovação, inclusão e qualidade. Avaliação, Campinas; Sorocaba, v. 18, n. 3, p. 519-545, nov. 2013. Disponível em: http://www.scielo.br/scielo.php?script=sci_arttext\&pid=S1414$40772013000300002 \&$ lang=pt. Acesso em: 27 mar. 2018.

ROBERTSON, Susan L. O Processo de Bolonha da Europa torna-se global: modelo, mercado, mobilidade, força intelectual ou estratégia para construção do estado? Revista Brasileira de Educação, Rio de Janeiro, v. 14, n. 42, p. 407-421, set./dez. 2009. Disponível em: http://www.scielo.br/scielo.php?script=sci_arttext\&pid=S1413$24782009000300002 \& l a n g=p t$. Acesso em: 27 mar. 2018.

SANTOS JÚNIOR, José da S.; REAL, Giselle C. M. A evasão na educação superior: o estado da arte das pesquisas no Brasil a partir de 1990. Avaliação, Campinas; Sorocaba, v. 22, n. 2, p. 385-402, jul. 2017. Disponível em: http://www.scielo.br/scielo.php?script=sci_arttext\&pid=S1414$40772017000200385 \&$ lang=pt. Acesso em: 27 mar. 2018.

SCHMIDT, João Pedro. O comunitário em tempos de público não estatal. Avaliação, Campinas; Sorocaba, v. 15, n. 1, p. 9-40, mar. 2010. Disponível em: http://www.scielo.br/scielo.php?script=sci_arttext\&pid=S1414$40772010000100002 \& l a n g=p t$. Acesso em: 27 mar. 2018.

SCHWARTZMAN, Simon. Demanda e políticas públicas para o ensino superior nos BRICS. Caderno CRH, Salvador, v. 28, n. 74, p. 267-289, maio/ago. 2015. Disponível em: http://www.scielo.br/scielo.php?script=sci_arttext\&pid=S0103$49792015000200267 \&$ lang=pt. Acesso em: 27 mar. 2018. 
SCHWARTZMAN, Simon; PILLAY, Pundy; PINHEIRO, Romulo (eds.). Higher education in the Brics countries: investigating the pact between higher education and society. Dordrecht: Springer, 2015. Disponível em: https://www.springer.com/gp/book/9789401795692. Acesso em: 27 mar. 2018.

SEGENREICH, Stella C. D.; CASTANHEIRA, Antonio M. Expansão, privatização e diferenciação da educação superior no Brasil pós-LDBEN/96: evidências e tendências. Ensaio, Rio de Janeiro, v. 17, n. 62, p. 55-86, jan./mar. 2009. Disponível em: http://www.scielo.br/scielo.php?script=sci_arttext\&pid=S0104$40362009000100004 \& l a n g=p t$. Acesso em: 27 mar. 2018.

SEGRERA, Francisco López. Tendencias de la educación superior en el mundo y en América Latina y el Caribe. Avaliação, Campinas; Sorocaba, v. 13, n. 2, p. 267-291, jul. 2008. Disponível em: http://www.scielo.br/scielo.php?script=sci_arttext\&pid=S1414$40772008000200003 \&$ lang=pt. Acesso em: 27 mar. 2018.

SEGRERA, Francisco López. Educación superior comparada: tendencias mundiales y de América Latina y Caribe. Avaliação, Campinas; Sorocaba, SP, v. 21, n. 1, p. 13-32, mar. 2016. Disponível em: http://www.scielo.br/scielo.php?script=sci_arttext\&pid=S1414$40772016000100013 \&$ lang=pt. Acesso em: 27 mar. 2018.

SERAFIM, Milena Pavan. O processo de mercantilização das instituições de educação superior: um panorama do debate nos EUA, na Europa e na América Latina. Avaliação, Campinas; Sorocaba, v. 16, n. 2, p. 241-265, jul. 2011. Disponível em: http://www.scielo.br/scielo.php?script=sci_arttext\&pid=S1414$40772011000200002 \&$ lang=pt. Acesso em: 27 mar. 2018.

SERAFIM Milena; DIAS, Rafael. Comentários sobre as transformações recentes na universidade pública brasileira. Avaliação, Campinas; Sorocaba, v. 20, n. 2, p. 335-351, jul. 2015. Disponível em: http://www.scielo.br/scielo.php?script=sci_arttext\&pid=S141440772015000200335\&lang=pt. Acesso em: 27 mar. 2018.

SEVERINO, Antônio Joaquim. O ensino superior brasileiro: novas configurações e velhos desafios. Educar, Curitiba, n. 31, p. 73-89, 2008. Disponível em: http://www.scielo.br/scielo.php?script=sci_arttext\&pid=S0104$40602008000100006 \& l a n g=p t$. Acesso em: 27 mar. 2018.

SEVERINO, Antônio Joaquim. Expansão do ensino superior: contextos, desafios, possibilidades. Avaliação, Campinas; Sorocaba, v. 14, n. 2, p. 253-266, jul. 2009. Disponível em: http://www.scielo.br/scielo.php?script=sci_arttext\&pid=S1414$40772009000200002 \&$ lang=pt. Acesso em: 27 mar. 2018.

SGUISSARDI, Valdemar. Educação superior no Brasil. Democratização ou massificação mercantil? Educação \& Sociedade, Campinas, v. 36, n. 133, p. 867-889, out./dez. 2015. Disponível em: http://www.scielo.br/scielo.php?script=sci_arttext\&pid=S0101$73302015000400867 \&$ lang=pt. Acesso em: 27 mar. 2018.

SOUSA, José Vieira. Qualidade na educação superior: lugar e sentido na relação públicoprivado. Cadernos Cedes, Campinas, v. 29, n. 78, p. 242-256, maio/ago. 2009. Disponível 
em: http://www.scielo.br/scielo.php?script=sci_arttext\&pid=S0101-

$32622009000200007 \&$ lang=pt. Acesso em: 27 mar. 2018.

SPATTI, Ana Carolina; SERAFIM, Milena Pavan; DIAS, Rafael de Brito. Universidade e pertinência social: alguns apontamentos para reflexão. Avaliação, Campinas; Sorocaba, v. 21, n. 2, p. 341-360, jul. 2016. Disponível em:

http://www.scielo.br/scielo.php?script=sci_arttext\&pid=S1414-

$40772016000200341 \& l a n g=p t$. Acesso em: 27 mar. 2018.

STROMQUIST, Nelly P. Educação Latino-americana em tempos globalizados. Sociologias, Porto Alegre, v. 14, n. 29, p. 72-99, jan./abr. 2012. Disponível em:

http://www.scielo.br/scielo.php?script=sci_arttext\&pid=S1517-

45222012000100004\&lang=pt. Acesso em: 27 mar. 2018.

TINTO, Vicent. Leaving College: rethinking the causes and cures of student attrition. 2. ed. Chicago, EUA: The University of Chicago Press, 1993.

UNITED STATES OF AMERICA. National Center for Education Statistics. The condition of education: undergraduate enrollment. Washington, 2017. Disponível em:

https://nces.ed.gov/programs/coe/indicator_cha.asp. Acesso em: 18 mar. 2018.

WIELEWICKI, Hamilton de Godoy; OLIVEIRA, Marlize Rubin. Internacionalização da educação superior: Processo de Bolonha. Ensaio, Rio de Janeiro, v. 18, n. 67, p. 215-234, abr./jun. 2010. Disponível em: http://www.scielo.br/pdf/ensaio/v18n67/a03v1867.pdf. Acesso em: 27 mar. 2018. 